\title{
Renal Genetics and Clinical Practice: The Present and the Possible
}

\author{
Richard Sandford ${ }^{a} \quad$ John Sedor ${ }^{b}$ \\ ${ }^{a}$ Academic Department of Medical Genetics, Addenbrooke's Treatment Centre, Addenbrooke's Hospital, \\ Cambridge, UK; ${ }^{b}$ Departments of Medicine and Physiology and Biophysics, Case Western Reserve University, and \\ Kidney Disease Research Center, Rammelkamp Center for Research and Education, Cleveland, Ohio, USA
}

The identification of the genetic basis of many mendelian diseases has resulted in the clinical application of molecular genetic testing, an outcome that has had a major impact on many clinical specialities over the last two decades [1]. The ability to detect highly penetrant, disease-causing mutations has allowed accurate diagnosis, personalized screening, reliable pre-symptomatic testing and preconception counselling to become widely available for many diseases. In addition, identification of causative genes has elucidated disease pathogenesis and permits the design and rapid testing of novel therapies. It has also added another valuable diagnostic tool that the clinician can access, which in some cases can replace invasive testing such as renal biopsy. However, both the physician and patient require a thorough understanding of the appropriate uses and limitations of genetic testing in clinical care $[2,3]$.

The pace at which gene discovery now occurs brings with it the promise of identifying the molecular architecture of all mendelian (single gene) diseases within the next few years rather than decades. In addition, the genetic basis of many complex diseases is also being elucidated in a way that was inconceivable only a few years ago. New sequencing technologies permit investors to generate and analyse extremely large genetic datasets from both selected and community-based populations. Gen-

\section{KARGER}

Fax +4161306 1234

E-Mail karger@karger.ch

www.karger.com
(C) 2010 S. Karger AG, Basel

$1660-2110 / 11 / 1181-0001 \$ 38.00 / 0$

Accessible online at:

www.karger.com/nec eration of a complete 'exome' or even a whole genome sequence will be a diagnostic and/or prognostic possibility for individuals with genetic disease in only a few years [4].

In this special edition of Nephron, a series of international experts in the field of renal genetics review our current knowledge base on a range of renal phenotypes with variable genetic influences. It is clear from the description of many different structural, glomerular and tubular diseases that the identification of the underlying genetic cause has had a major impact not only on our understanding of disease pathogenesis and the design of novel therapies but also on the routine clinical diagnosis and management of diseases seen in the nephrology clinic. This also extends to the identification of genetic factors important in the development of chronic kidney disease and host-recipient interactions that influence outcomes in renal transplantation.

The identification of the genetic cause of many renal diseases such as autosomal dominant polycystic kidney disease, nephronophthisis, disorders of tubular function and familial renal cancer has allowed accurate and early diagnosis for individuals and their families and access to predictive testing. The latter is associated with accurate risk assessment and targeted screening such as in von Hippel-Lindau syndrome (page e21-e26). It may also 
allow for improved prognostic information to be provided such as delayed progression to end-stage renal failure in individuals with a PKD2 mutation (page c19-c30) or risk of disease recurrence in a renal transplant in atypical haemolytic uraemic syndrome (page c37-c42). The identification of the molecular basis of tuberous sclerosis complex not only established accurate genetic diagnosis and the availability of prenatal diagnosis for a potentially life-threatening neurodevelopmental disorder but also the rational basis for the use of mTOR inhibitors in the treatment of renal angiomyolipomas which occur in a high proportion of patients with tuberous sclerosis complex (page e15-e20).

These examples illustrate the benefit of identifying mutations that accurately predict disease. However, it is clear that for some conditions disease penetrance and expression are dependent on the interaction of a few or many genes (oligogenic and polygeneic inheritance, respectively). In this special edition, examples that illustrate oligogenic inheritance include nephronophthisis and atypical haemolytic uraemic syndrome. These present new challenges to our understanding of disease and how to interpret and communicate genetic data in the clinical setting. We are only just beginning to understand the role of genetics in complex or polygenic diseases, but how this information may be of clinical benefit remains unclear at present.

Historically, genetic variants underlying disease phenotypes have been identified by the targeted sequencing of very small areas of the human genome identified by linkage analysis, detection of visible structural chromosomal anomalies and sequencing of candidate genes. This is being replaced by the ability to use cheap, very high throughput sequencing to cover all exons or the whole genome. It is therefore possible that all individuals, especially those with familial renal disease such as FSGS for which there are few mutations described, will have a mutation identified. The challenge then becomes how this information can be used for the benefit of patients, their families, and for all individuals at risk of developing CKD [5]. To support this rapid advance in renal genetics, it will also be necessary to frame the information around accurate phenotypic data.

Thus, there will be an increasing need for clinical investigation and disease registries to assemble large, wellcharacterized cohorts. This must be carried out in parallel if not ahead of the implementation of next-generation sequencing technologies as a tool available to all researchers.

Genetic data are also likely to influence many more aspects of the care of renal patients in ways that we currently cannot predict. Potential examples include stratifying patients with CKD into fast and slow progressors based on the identification of risk alleles and donor selection to minimize further the risk of early and late graft dysfunction.

However, it is the promise of rationale drug development based on novel target identification that will drive many of the genetic studies based on next-generation sequencing. A similar issue of Nephron in even 5 years is likely to describe many new disease-associated genes and the challenges facing nephrologists of using the information to inform and manage patients with common and rare renal diseases.

\section{References}

1 Guay-Woodford LM, Knoers NV: Genetic testing: considerations for pediatric nephrologists. Semin Nephrol 2009;29:338-348.

2 Kaphingst KA, McBride CM: Patient responses to genetic information: studies of patients with hereditary cancer syndromes identify issues for use of genetic testing in nephrology practice. Semin Nephrol 2010; 30:203-214.

3 Khoury MJ, Feero WG, Reyes M, Citrin T, Freedman A, Leonard D, Burke W, Coates R, Croyle R, Edwards K, Kardia S, McBride C, Manolio T, Randhawa G, Rasooly R, St PJ, Terry S: The genomic applications in practice and prevention network. Genet Med 2009;11:488-494.
4 Ashley EA, Butte AJ, Wheeler MT, Chen R, Klein TE, Dewey FE, Dudley JT, Ormond KE, Pavlovic A, Morgan AA, Pushkarev D, Neff NF, Hudgins L, Gong L, Hodges LM, Berlin DS, Thorn CF, Sangkuhl K, Hebert JM, Woon M, Sagreiya H, Whaley R, Knowles JW, Chou MF, Thakuria JV, Rosenbaum AM, Zaranek AW, Church GM, Greely HT, Quake SR, Altman RB: Clinical assessment incorporating a personal genome. Lancet 2010;375:1525-1535.

5 Laberge AM, Burke W: Clinical and public health implications of emerging genetic technologies. Semin Nephrol 2010;30:185194. 